\title{
The Effect of Traditional Thai Massage on Quality of Sleep in Adults with Sleep Problem
}

\author{
Warangkana Chompoopan ${ }^{1, *}$, Wichai Eungpinichpong ${ }^{2}$, \\ Worawut Chompoopan ${ }^{1}$ and Chinakorn Sujimongkol ${ }^{3}$
}

\author{
${ }^{I}$ Sirindhorn College of Public Health, Khon Kaen 40000, Thailand \\ ${ }^{2}$ Research Center in Back Neck Other Joint Pain and Human Performance, \\ Faculty of Associated Medical Sciences, Khon Kaen University, Khon Kaen 40002, Thailand \\ ${ }^{3}$ Loei Hospital, Loei 42000, Thailand
}

('Corresponding author's e-mail: warangkana@scphkk.ac.th)

Received: 7 November 2020, Revised: 18 May 2021, Accepted: 25 May 2021

\begin{abstract}
Sleep problem or insomnia is one of the most common causes of health problems, affecting around $10-20 \%$ of the world population. Traditional Thai massage (TTM) is a popular alternative treatment in Thailand for reducing fatigue and improving sleep quality. This study aimed to examine the effect of traditional Thai massage on sleep quality in adults. Twenty-eight adults with poor sleep quality (based on Verran and Snyder-Halpern sleep scale) participated. They were randomly allocated into a control group $(\mathrm{n}=14)$ and a TTM group $(\mathrm{n}=14)$. Participants in the TTM group received three 90 -min whole body traditional Thai massage sessions within one week, whereas the control group participants maintained their daily lives. Quality of sleep was assessed before and a day after the massage sessions. The outcome measure was the Verran and Snyder-Halpern sleep scale. The within-group data was analyzed by Paired ttest, whereas ANCOVA did the between-group data.

The results showed that the participants in the TTM group had significantly decreased score of sleep disturbance $(31.63 \pm 2.95$ vs $45.47 \pm 3.24, p<0.001)$ and increased the effectiveness score $(70.73 \pm 7.33$ vs $53.47 \pm 4.23, p<0.001)$ after the last session of massage as compared to those of the control group. We conclude that TTM could significantly improve sleep quality without any adverse effects.
\end{abstract}

Keywords: Sleep problem, Thai massage, Manual therapy

\section{Introduction}

Sleep problem or insomnia is one of the most common causes of health problems, affecting around 10 to $20 \%$ of the world population [1], associated with a higher risk of incidence of cardiovascular disease [2]. Moreover, poor sleep quality led to many diseases such as behavior, psychiatric disorder, diabetes mellitus, and hypertension which could be major causes of mortality [3]. The prevalence rate of sleep problem was $9.8 \%$ in the U.K. [4], $11.3 \%$ in Canada, $29.2 \%$ in the US [5], and $33-45 \%$ in Australian adults [6], respectively. By 2030, the number of older adults from 8 countries across Africa and Asia is projected to rise to 1.578 million, corresponding to more than 260 million people possibly experiencing sleep problems. Overall, $16.6 \%$ of the data reported extreme nocturnal sleep problems in low-income settings [7].

The overall prevalence of insomnia in Thai adults was $40.8 \%$ and is commonly found in the Thai population [8]. Sleep quality was associated with all the academic performance indicators in adolescents [9] and cognitive function in adults [10]. Sleep efficiency is defined as total sleep time divided by time spent in bed trying to sleep. It tends to decline with age and affects psychological wellbeing $[11,12]$. Previous studies have shown an association between sleep efficiency, subjective sleep quality, and various health outcomes $[13,14]$. Quality learning and memory are linked to sleep. Sleep problems have an impact on physical health [15], which includes neuroendocrine, immune, metabolic system [16-18], neurogenesis, emotional process, and mood disorder [19]. Previous studies in adults with sleep problems were related to emotional symptoms [20], which increased the risk of depression [21] and anxiety [22].

Sleepiness is one of the common problems in the general population that can be caused by reduced sleep duration and quality in healthy adults. The appropriate sleep duration per night for adults is 7 to $9 \mathrm{~h}$ 
for young adults and adults, and 7 to $8 \mathrm{~h}$ of sleep for older adults [23]. The duration of total sleep is one of the essential factors for maintaining wellbeing in healthy people. The most prevalent sleep problems have been found in people aged 45 or more [24]. Without proper early intervention, sleep problems can lead to chronic diseases, e.g., hypertension [25], allergic rhinitis, and emotional disturbance [26] in the future. Thus, to prevent these diseases through management of sleep problems is essential.

Many methods have been suggested for the management of sleep problems. These include tranquilizers, behavior therapy, and regular exercise. However, these medications always have side effects such as morning hangovers and memory disturbance after taking them before bedtime. People who undergo behavior therapy and exercise always need to put effort into many sessions and participate in a group. Previous studies found that massage could reduce stress, the sensitivity of myofascial trigger points [27], pain [28], and improve sleep quality [29,30]. Traditional Thai massage (TTM) has been used to promote physical and mental general relaxation for a long time. Previous studies found that TTM could reduce pain [31], and promote relaxation [32] without any adverse effect. Moreover, it has been noted that clients who underwent TTM tended to sleep well at night after receiving this kind of treatment. However, its positive effect on sleep quality has not been verified.

The current study aimed to determine the effect of TTM on sleep quality in adults who had sleep problems. It was hypothesized that TTM could increase sleep quality in this population.

\section{Materials and methods}

\section{Research design and sample}

This study employed a randomized control trial to compare the mean difference between 2 groups, including a control and a TTM group. The study was conducted in a traditional Thai massage clinic at Sirindhorn College of Public Health KhonKaen. Ethical approval was obtained from the KhonKaen University Ethics Committee for Human Research with reference number HE 592404.

The sample size for this study was estimated based on a previous pilot study where $80 \%$ power and $95 \%$ confidence interval. Thirty-two adults were recruited from the community and posted on board at massage clinics. Inclusion criteria of the study were people aged 18 years or more and had insomnia assessed by a screening Pittsburgh Sleep Quality Index (PSQI). The participants, who had a history of vascular disease, bone disease, used psychiatric, narcotic, and sedative drugs, were excluded. Five adults were not included because of the following reasons: Not meeting inclusion criteria $(\mathrm{n}=2)$, declined to participate $(n=1)$, and other personal reasons $(n=2)$. Finally, the study sample consisted of 28 participants who were randomly allocated into two groups using simple randomization: (1) a treatment group who received Traditional Thai massage $\quad(n=14)$ and $(2)$ a control group without Traditional Thai massage $(n=14)$

\section{Interventions}

Participants in the TTM group received 3 sessions of 90-min per session of whole-body Traditional Thai massage within a week following most routine practices of TTM. The protocol of TTM used in this study is based on a standard full-body Thai massage on energy or Sensib lines and TTM expert suggestions. The TTM protocol consisted of 3 major steps. Firstly, the participant laid down on the bed. The massage therapist applied a 20 -s sustained pressure by hand on the upper arm to the brachial artery and then on the lower limb to the femoral artery. This technique was initiated to stimulate blood flow for tissue perfusion to the upper and lower extremity. Secondly, the therapist applied gentle and deep pressure by thumbs, palms, or elbow along the ten energy lines of TTM that covered major muscles and fascia of arms, legs, back, and neck. Deep pressure massage along each of the lines was repeated in 5 rounds.

Finally, gentle stretches were applied for those muscles at the end of the massage session. Participants in the control group maintained their daily activities without undergoing TTM.

\section{Outcome measure}

Verran and Snyder-Halpern sleep Scale (VSH Scale) was the tool for outcome measure in this study. This tool consisted of 16 items which included three domains of sleep subscales: Disturbance (interruption and delays in sleep), effectiveness (how well sleep refreshed the individual), and supplementation [33]. It was a questionnaire that consisted of a visual analog scale where the participants assessed the quality of their previous night's sleep. The participants marked across on a $100 \mathrm{~mm}$ line representing their feelings of sleep quality, where 0 indicates that the sleep behavior or quality is not presented, and 100 indicates that it is the most frequently experienced. 


\section{Procedure}

The process of data collection consisted of 3 steps. Firstly, the objective and design of the study were explained to all participants before they gave informed consent at the Thai Traditional massage clinic. Secondly, self-assessment of insomnia was obtained using a Thai version screening of the Pittsburgh Sleep Quality Index (PSQI), and sleep quality was administered using a Thai version of the Verran and Snyder Halpern Sleep Scale (VSH Scale) [34]. Thirdly, all subjects were randomly allocated into the two groups using a pre-generated simple randomized by Lottery.

\section{Data analysis}

Data in this study were analyzed using SPSS for Windows Version 19 (IBM Corp. Released 2010, IBM SPSS Statistics for Windows, and Version 19.0 Armonk, NY: IBM Corp.) under the license of KhonKaen University. The normal distributions of continuous data of each variable were tested by the Shapiro-Wilk test. The data were analyzed by an Independent t-test for comparing baseline between the treatment and the control groups. Analysis of covariance (ANCOVA) was obtained for between-group comparison. Paired t-test was used for within-group comparison. A difference at the level of $p<0.05$ was considered statistically significant.

\section{Results and discussion}

Traditional Thai massage can provide several benefits to the body and mind, such as reduced pain, stress, and increased quality of life, but there are no data to support sleep quality. The results of this study showed the effect of Traditional Thai massage by sleep assessment tool.

The demographic variables based on gender, age, marital status, income, and occupation were stratified between the TTM and the control groups. Fourteen participants were allocated in each group. Most of them were female ( 9 in the TTM group and 11 in the control group). The mean age of patients was 41.50 (9.25) and 43.79 (10.21) years, respectively.

Baseline data before the intervention were compared between the two groups and found no significant difference in terms of sleep disturbance scale, effectiveness scale, and supplementation scale. The baseline data between the two groups were balanced for all subscales (Table 1).

Table 1 Baseline data before the intervention of both groups.

\begin{tabular}{|c|c|c|c|c|c|c|}
\hline \multirow{2}{*}{ VSH Scale } & \multirow{2}{*}{$\begin{array}{c}\text { TTM } \\
\text { Mean (S.D.) }\end{array}$} & \multirow{2}{*}{$\begin{array}{c}\text { Control } \\
\text { Mean (S.D.) }\end{array}$} & \multirow{2}{*}{$\begin{array}{c}\text { Mean } \\
\text { difference }\end{array}$} & \multicolumn{2}{|c|}{$95 \% \mathrm{CI}$} & \multirow{2}{*}{$p$-value } \\
\hline & & & & Lower & Upper & \\
\hline Disturbance scale & $70.73(3.50)$ & $69.24(4.09)$ & 1.49 & -1.47 & 4.44 & 0.310 \\
\hline Effectiveness scale & $60.84(4.25)$ & $63.73(7.78)$ & -2.89 & -7.76 & 1.99 & 0.234 \\
\hline Supplementation scale & $65.77(4.35)$ & $64.59(4.73)$ & 1.18 & -2.36 & 4.73 & 0.601 \\
\hline
\end{tabular}

Within-group analysis of the TTM group revealed that after receiving the first session of TTM, the participants had significantly decreased mean score in disturbance scale and supplementation scale, and increased in effectiveness scale of VSH (Figure 1). 


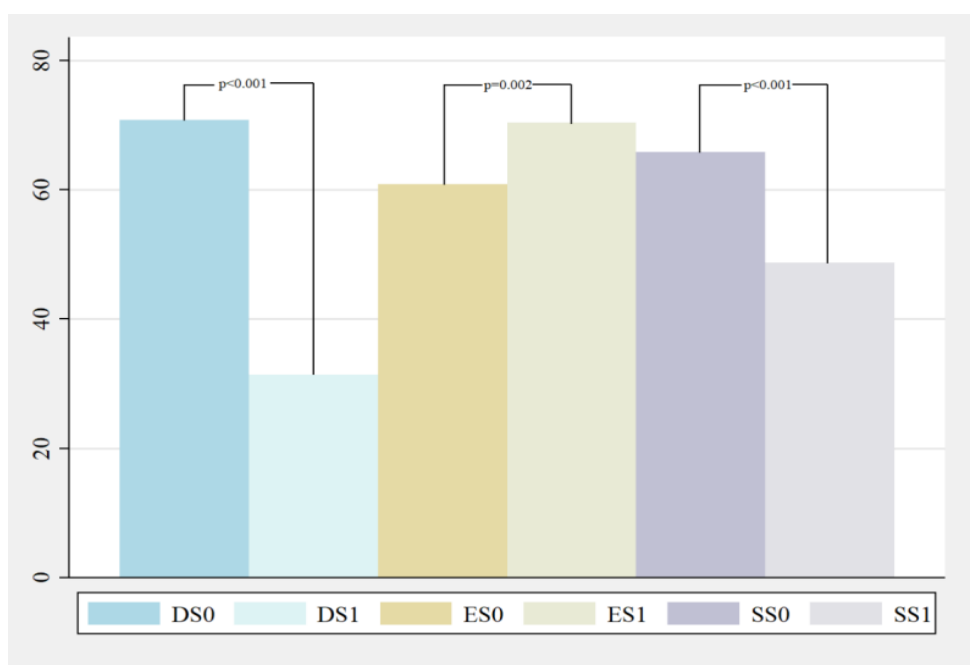

Figure 1 Within-group comparison of the TTM group on Disturbance scale, Effectiveness scale, and Supplementation scale;

DS0 $=$ Disturbance scale before receiving TTM, DS1 $=$ Disturbance scale after receiving TTM.

ES0 $=$ Effectiveness scale before receiving TTM, ES1 $=$ Effectiveness scale after receiving TTM.

$\mathrm{SS} 0=$ Supplementation scale before receiving TTM, ES1= Supplementation scale after receiving TTM.

Within-group analysis of the control group after the first session of TTM group, the participants had significantly decreased mean score in disturbance scale and supplementation scale, except for effectiveness scale of VSH (Figure 2).

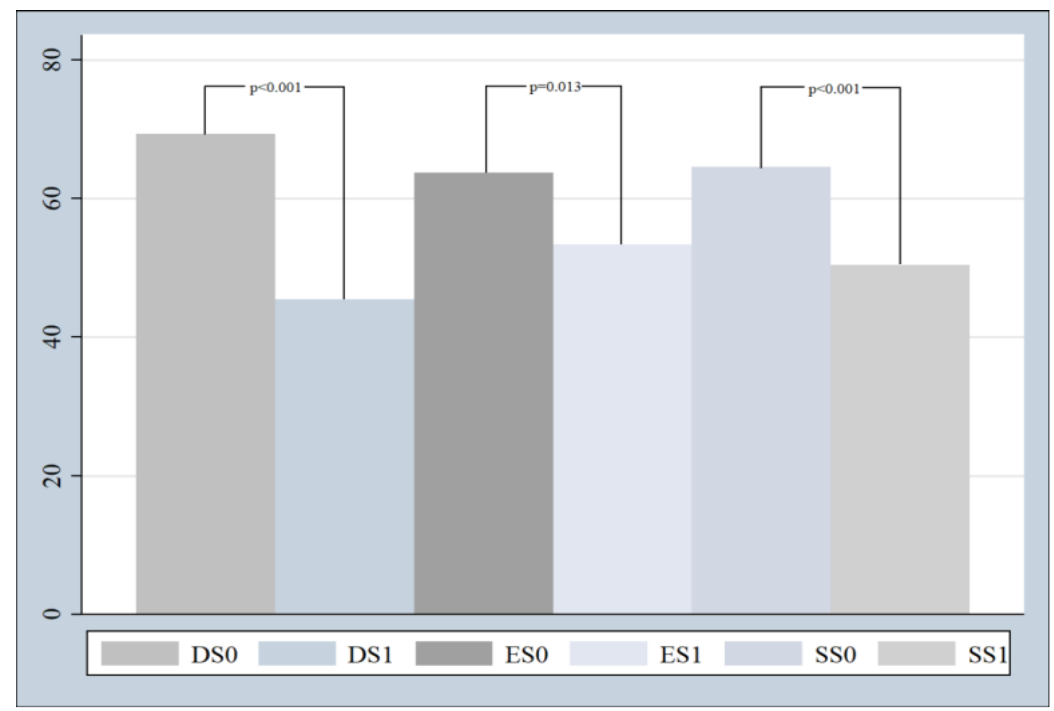

Figure 2 within group comparison of the control group on Disturbance scale, Effectiveness scale, and Supplementation scale;

DS0 $=$ Disturbance scale before receiving TTM, DS1 $=$ Disturbance scale after receiving TTM.

ES0 $=$ Effectiveness scale before receiving TTM, ES1= Effectiveness scale after receiving TTM.

$\mathrm{SS} 0=$ Supplementation scale before receiving TTM, ES1= Supplementation scale after receiving TTM.

For 1-week within group comparison, paired t-test of the TTM group, the participants had significantly decreased mean score in disturbance scale and supplementation scale, and increased in effectiveness scale of VSH after TTM $(p<0.001)$ (Table 2). 
Table 2 Mean score of 3 subscales of VSH before and after TTM for 3 sessions in 1 week (TTM group).

\begin{tabular}{|c|c|c|c|c|c|c|}
\hline \multirow{2}{*}{ VSH Scale } & \multirow{2}{*}{$\begin{array}{c}\text { Before } \\
\text { TTM } \\
\text { Mean (S.D.) }\end{array}$} & \multirow{2}{*}{$\begin{array}{c}\text { After } \\
\text { TTM } \\
\text { Mean (S.D.) }\end{array}$} & \multirow{2}{*}{$\begin{array}{c}\text { Mean } \\
\text { difference }\end{array}$} & \multicolumn{2}{|c|}{$95 \% \mathrm{CI}$} & \multirow{2}{*}{$p$-value } \\
\hline & & & & Lower & Upper & \\
\hline Disturbance scale & $70.73(3.50)$ & $30.85(4.70)$ & 39.88 & 34.83 & 44.93 & $<0.001$ \\
\hline Effectiveness scale & $60.84(4.25)$ & $75.22(8.59)$ & -14.38 & -20.79 & -7.96 & $<0.001$ \\
\hline Supplementation scale & $65.77(4.39)$ & $39.24(8.00)$ & 26.53 & 19.17 & 33.88 & $<0.001$ \\
\hline
\end{tabular}

Paired t-test of 1-week within-group comparison of the control group did not show any significant difference in the subscale of the "Effectiveness scale" $(p>0.05)$. The participants had a decreased mean score in both disturbance scale $(p<0.001)$ and supplementation scale $(p<0.002)$ (Table 3$)$.

Table 3 Mean score of 3 subscales of VSH of the control group in 1 week (control group).

\begin{tabular}{|c|c|c|c|c|c|c|}
\hline \multirow{2}{*}{ VSH Scale } & \multirow{2}{*}{$\begin{array}{c}\text { Before } \\
\text { TTM } \\
\text { Mean (S.D.) }\end{array}$} & \multirow{2}{*}{$\begin{array}{c}\text { After } \\
\text { TTM } \\
\text { Mean (S.D.) }\end{array}$} & \multirow{2}{*}{$\begin{array}{c}\text { Mean } \\
\text { difference }\end{array}$} & \multicolumn{2}{|c|}{$95 \% \mathrm{CI}$} & \multirow{2}{*}{$p$-value } \\
\hline & & & & Lower & Upper & \\
\hline Disturbance scale & $69.24(4.08)$ & $45.28(5.26)$ & 23.96 & 18.82 & 29.12 & $<0.001$ \\
\hline Effectiveness scale & $63.73(7.78)$ & $55.52(9.41)$ & 8.21 & 2.97 & 19.39 & 0.240 \\
\hline Supplementation scale & $64.59(4.73)$ & $55.14(7.22)$ & 9.45 & 3.50 & 15.41 & $<0.002$ \\
\hline
\end{tabular}

Between-group comparison by ANCOVA showed significant difference in disturbance subscale, and effectiveness sub scale after receiving 3 sessions of TTM. However, it did not show any significant difference in sub scale of supplementation before and after TTM $(p>0.05)$ (Table 4).

Table 4 Between-group comparison of mean scores of 3 subscales of VSH before and after receiving 3 sessions of TTM in 1 week.

\begin{tabular}{|c|c|c|c|c|c|c|}
\hline \multirow{2}{*}{ VSH Scale } & \multirow{2}{*}{$\begin{array}{c}\text { TTM } \\
\text { Mean (S.D.) }\end{array}$} & \multirow{2}{*}{$\begin{array}{c}\text { Control } \\
\text { Mean (S.D.) }\end{array}$} & \multirow{2}{*}{$\begin{array}{c}\text { Mean } \\
\text { difference }\end{array}$} & \multicolumn{2}{|c|}{$95 \%$ CI } & \multirow{2}{*}{$p$-value } \\
\hline & & & & Lower & Upper & \\
\hline Disturbance scale & $31.63(2.95)$ & $45.47(3.24)$ & -13.84 & -16.30 & -11.15 & $<0.001$ \\
\hline Effectiveness scale & $70.73(7.33)$ & $53.47(4.23)$ & 17.26 & 12.47 & 22.04 & $<0.001$ \\
\hline Supplementation scale & $48.00(16.00)$ & $50.49(7.32)$ & -2.49 & -7.50 & 3.91 & 0.531 \\
\hline
\end{tabular}

Mean adjusted baseline as the covariate

\section{Discussion}

This study aimed to examine the effects of TTM on the quality of sleep in adults. The results indicated that participants in the TTM group could improve their quality of sleep compared with those in the control group. Sleep quality improved significantly even at the first session after receiving TTM on the three subscales. The results of this study reveal that at the last session of TTM for three consecutive days, the TTM could significantly improve the quality of sleep without any adverse effect. These results were in line with previous studies, which have shown that massage therapy promotes sleep quality and reduces anxiety $[35,36]$. In Thailand, TTM is the kind of method used in the primary health care system that is widely used for promoting muscle relaxation [37], reduces psychological stress [38], increases parasympathetic activity, and may indirectly affect sleep [39]. 
Overall, the results of this study contributed to the body of knowledge related to the effects of TTM in adults with sleep problems. TTM may also benefit poor sleepers who likely have anxiety, pain, and stress. A possible mechanism of TTM on improving sleep quality might be that TTM, a type of deep massage, could stimulate mechanoreceptors, causing a reflex relaxation effect [40] that contributes to having a good sleep. The results of this study are in line with a previous study that found that massage therapy could help improve the quality of sleep in patients after coronary artery bypass with sleep problems [30]. The current study results also support the evidence that massage is an effective technique for improving sleep, reducing fatigue [30,31] without any adverse effects such as bruise and delayed onset muscle soreness [6].

\section{Conclusions}

The findings of this study showed significant differences in the disturbance and effectiveness scale of VSH resulting from Thai massage. Since this treatment is generally safe, it might be used as an alternative therapy to treat people with sleep problems. The long-term effects of TTM on sleep could be explored in the future.

\section{Acknowledgments}

This study would not have been possible without the kind cooperation of the Thai traditional massage clinic at Sirindhorn College of Public Health KhonKaen and the 28 participants. More importantly, Sirindhorn College of Public Health has provided financial support to the research project.

\section{References}

[1] JM Merrigan, DJ Buysse, JC Bird and EH Livingston. Insomnia. J. Am. Med. Assoc. 2013; 309, 733.

[2] SM Bertisch, BD Pollock, MA Mittleman, DJ Buysse, LA Bazzano, DJ Gottlieb, LA Bazzano, DJ Gottlieb and $\mathrm{S}$ Redline. Insomnia with objective short sleep duration and risk of incident cardiovascular disease and all-cause mortality: Sleep heart health study. Sleep 2018; 41, zsy047.

[3] S Garbarino, P Lanteri, P Durando, N Magnavita and WG Sannita. Co-morbidity, mortality, quality of life and the healthcare/welfare/social costs of disordered sleep: A rapid review. Int. J. Environ. Res. Publ. Health 2016; 13,831.

[4] YS Bin, NS Marshall and N Glozier. Sleeping at the limits: The changing prevalence of short and long sleep durations in 10 countries. Am. J. Epidemiol. 2013; 177, 826-33.

[5] ES Ford, TJ Cunningham and JB Croft. Trends in self-reported sleep duration among US adults from 1985 to 2012. Sleep 2015; 38, 829-32.

[6] RJ Adams, SL Appleton, AW Taylor, TK Gill, C Lang, RD McEvoy and NA Antic. Sleep health of Australian adults in 2016: Results of the 2016 Sleep Health Foundation national survey. Sleep Health 2017; 3, 35-42.

[7] S Stranges, W Tigbe, FX Gómez-Olivé, M Thorogood and NB Kandala. Sleep problems: An emerging global epidemic? Findings from the INDEPTH WHO-SAGE study among more than 40,000 older adults from 8 countries across Africa and Asia. Sleep 2012; 35, 1173-81.

[8] P Udomratn. Prevalence of insomnia in the Thai population. ASEAN J. Psychiatr. 2008; 9, 42-7.

[9] M Adelantado-Renau, A Diez-Fernandez, MR Beltran-Valls, A Soriano-Maldonado and D MolinerUrdiales. The effect of sleep quality on academic performance is mediated by Internet use time: DADOS study. J. Pediatr. 2019; 95, 410-8.

[10] K Crowley. Sleep and sleep disorders in older adults. Neuropsychol. Rev. 2011; 21, 41-53.

[11] MF Leblanc, S Desjardins and A Desgagné. Sleep cognitions associated with anxiety and depression in the elderly. Clin. Interv. Aging 2015; 10, 575-82.

[12] Y Song, DL Washington, EM Yano, SM McCurry, CH Fung, JM Dzierzewski, JC Rodriguez, S Jouldjian, MN Mitchell, CA Alessi and JL Martin. Caregiving-related sleep problems and their relationship to mental health and daytime function in female veterans. Behav. Sleep Med. 2018; 16, $371-9$.

[13] SY Tsai, PL Lee, JW Lin and CN Lee. Cross-sectional and longitudinal associations between sleep and health-related quality of life in pregnant women: A prospective observational study. Int. J. Nurs. Stud. 2016; 56, 45-53. 
[14] A Monterrosa-Castro, M Marrugo-Flórez, I Romero-Pérez, AM Fernández-Alonso, P Chedraui, FR Pérez-López. Assessment of sleep quality and correlates in a large cohort of Colombian women around menopause. Menopause 2013; 20, 464-9.

[15] DF Kripke, L Garfinkel, DL Wingard, MR Klauber and MR Marler. Mortality associated with sleep duration and insomnia. Arch. Gen. Psychiatr. 2002; 59, 131-6.

[16] BS McEwen and IN Karatsoreos. Sleep deprivation and circadian disruption: Stress, allostasis, and allostatic load. Sleep Med. Clin. 2015; 10, 1-10.

[17] K Spiegel, E Tasali, R Leproult and EV Cauter. Effects of poor and short sleep on glucose metabolism and obesity risk. Nat. Rev. Endocrinol. 2009; 5, 253-61.

[18] KL Knutson. Impact of sleep and sleep loss on glucose homeostasis and appetite regulation. Sleep Med. Clin. 2007; 2, 187-97.

[19] BR Miller and R Hen. The current state of the neurogenic theory of depression and anxiety. Curr. Opin. Neurobiol. 2015; 30, 51-8.

[20] T Eller, A Aluoja, V Vasar and M Veldi. Symptoms of anxiety and depression in Estonian medical students with sleep problems. Depress. Anxiety 2006; 23, 250-6.

[21] L Zhai, Y Zhang and D Zhang. Sedentary behaviour and the risk of depression: A meta-analysis. $B r$. J. Sports Med. 2015; 49, 705-9.

[22] L Staner. Sleep and anxiety disorders. Dialogues Clin. Neurosci. 2003; 5, 249-58.

[23] M Hirshkowitz, K Whiton, SM Albert, C Alessi, O Bruni, L DonCarlos, N Hazen, J Herman, ES Katz, L Kheirandish-Gozal, DN Neubauer, AE O’Donnell, M Ohayon, J Peever, R Rawding, RC Sachdeva, B Setters, MV Vitiello, JC Ware and PJA Hillard. National Sleep Foundation's sleep time duration recommendations: Methodology and results summary. Sleep Health 2015; 1, 40-3.

[24] M Ohayon. Epidemiological study on insomnia in the general population. Sleep 1996; 19, S7-S15.

[25] XM Sun, S Yao, SJ Hu, ZY Liu, YJ Yang, ZY Yuan, WM Ye, LJ and XF Wang. Short sleep duration is associated with increased risk of pre-hypertension and hypertension in Chinese early middle-aged females. Sleep Breath 2016; 20, 1355-62.

[26] JG Ellis, P Gehrman, CA Espie, D Riemann and ML Perlis. Acute insomnia: Current conceptualizations and future directions. Sleep Med. Rev. 2012; 16, 5-14.

[27] V Buttagat, W Eungpinichpong, U Chatchawan and S Kharmwan. The immediate effects of traditional Thai massage on heart rate variability and stress-related parameters in patients with back pain associated with myofascial trigger points. J. Bodyw. Mov. Ther. 2011; 15, 15-23.

[28] N Donoyama and M Shibasaki. Differences in practitioners' proficiency affect the effectiveness of massage therapy on physical and psychological states. J. Bodyw. Mov. Ther. 2010; 14, 239-44.

[29] F Kashani and P Kashani. The effect of massage therapy on the quality of sleep in breast cancer patients. Iran J. Nurs. Midwifery Res. 2014; 19, 113-8.

[30] FB Nerbass, MIZ Feltrim, SAD Souza, DS Ykeda and G Lorenzi-Filho. Effects of massage therapy on sleep quality after coronary artery bypass graft surgery. Clinics 2010; 65, 1105-10.

[31] S Mackawan, W Eungpinichpong, R Pantumethakul, U Chatchawan, $\mathrm{T}$ Hunsawong and $\mathrm{P}$ Arayawichanon. Effects of traditional Thai massage versus joint mobilization on substance $\mathrm{P}$ and pain perception in patients with non-specific low back pain. J. Bodyw. Mov. Ther. 2007; 11, 9-16.

[32] T Sripongngam, W Eungpinichpong, D Sirivongs, J Kanpittaya, K Tangvoraphonkchai and S Chanaboon. Immediate effects of traditional Thai massage on psychological stress as indicated by salivary alpha-amylase levels in healthy persons. Med. Sci. Monit. 2015; 21,216-21.

[33] R Snyder-Halpern and JA Verran. Instrumentation to describe subjective sleep characteristics in healthy subjects. Res. Nurs. Health 1987; 10, 155-63.

[34] A Kaewlue, S Banharak, L Panpanit, K Norachan and S Chanaboon. Effects of a sleep-promoting program on sleep quality among older patients at Special Medical Ward Chaloemphrakiat $9^{\text {th }}$ floor Chaiyaphum Hospital: A program development and pilot study. Int. J. Multidisciplin. Res. Publ. 2020; 2,7-12.

[35] C Ayik and D Ozden. The effects of preoperative aromatherapy massage on anxiety and sleep quality of colorectal surgery patients: A randomized controlled study. Complement. Ther. Med. 2018; 36, 93-9.

[36] G Arslan, O Ceyhan and M Mollaoglu. The influence of foot and back massage on blood pressure and sleep quality in females with essential hypertension: a randomized controlled study. J. Hum. Hypertens. 2020; 34,741-44.

[37] V Buttagat, T Narktro, K Onsrira and C Pobsamai. Short-term effects of traditional Thai massage on electromyogram, muscle tension and pain among patients with upper back pain associated with myofascial trigger points. Complement. Ther. Med. 2016; 28, 8-12. 
[38] T Sripongngam, W Eungpinichpong, D Sirivongs, J Kanpittaya, K Tangvoraphonkchai and S Chanaboon. Immediate effects of traditional Thai massage on psychological stress as indicated by salivary alpha-amylase levels in healthy persons. Med. Sci. Monit. 2015; 21, 216-21.

[39] L Wang, JL He and XH Zhang. The efficacy of massage on preterm infants: A meta-analysis. Am. J. Perinatol. 2013; 30, 731-8.

[40] CA Moyer, J Rounds and JW Hannum. A meta-analysis of massage therapy research. Psychol. Bull. 2004; 130, 3-18. 